\title{
Research on the Spatial Spillover Effect of the Collaborative Innovation of Science and Technology in the Pearl River Delta Urban Agglomeration
}

\author{
Yan $\mathrm{Wu}^{1}$ \\ ${ }^{1}$ Department of International Economics and Trade Beijing Institute of Technology, Zhuhai Zhuhai, China
}

\begin{abstract}
This paper uses spatial panel VAR model to study the spatial spillover of the collaborative innovation of Science and technology in the Pearl River Delta urban agglomeration from 2010 to 2018. The empirical results show that a positive shock on the collaborative innovation of Science and technology of a city in the Pearl River Delta urban agglomeration will spread to other cities in the Pearl River Delta urban agglomeration, and will have a positive impact on the collaborative innovation of Science and technology and $\mathrm{R} \& \mathrm{D}$ input variables of other cities in the second period; A positive shock on the R \& D input of a city will make the collaborative innovation of Science and technology and R \& D input variables of the city and other cities have a positive impact in the second period; the collaborative innovation of Science and technology and R \& D input variables have positive external effects in the Pearl River Delta urban agglomeration. Finally, some suggestions are put forward.
\end{abstract}

\section{Introduction}

In recent years, the Chinese governments at all levels have issued a large number of government documents on the scientific and technological innovation. "The opinions on deepening the reform of science and technology system and accelerating the construction of national innovation system"issued by the State Council in September 2012 clearly pointed out the opportunities and challenges faced by the science and technology development in China. Facing the new situation and new requirements, the independent innovation ability is not strong enough, and the scientific and technological system and mechanism are not suitable for the requirements of economic and social development and international competition. We should adhere to innovation driven and service development, adhere to the enterprise as main body, collaborative innovation, highlight the main role of enterprise in technology innovation aspect, and strengthen the close combination of industry, University, research and application. In 2015, the State Council issued "the implementation plan for deepening the reform of the science and technology system", which proposed that by 2020, the market-oriented mechanism of technological innovation would be more perfect, and enterprises, scientific research institutes, universities and other innovative subjects would be full of vitality and efficient cooperation. In 2016, the State Council issued "the outline of national innovation driven development strategy", which proposed to optimize the layout of regional innovation and create regional economic growth pole. The agglomeration and flow of innovation elements can promote the rational division of labor of industries and promote the overall improvement of regional innovation ability and competitiveness. The Guangdong provincial government has also issued a number of policy measures, such as "some policy opinions of Guangdong Provincial People's Government on accelerating scientific and technological innovation", "Notice of Guangdong Provincial People's Government on printing and distributing the construction scheme of Guangdong Province's science and technology innovation platform system", "Regulations of Guangdong Province on promoting the transformation of scientific and technological achievements" and "planning of Guangzhou Shenzhen Science and technology innovation corridor".

Domestic and foreign scholars have done the following research on regional collaborative innovation and its spatial spillover.

In the research of regional collaborative innovation of science and technology, Wang Weidong (2011) compared and analyzed the innovation ability of 16 cities in the Yangtze River Delta from four aspects of innovation economic foundation, urban innovation input capacity, innovation environment level and innovation output capacity, and put forward countermeasures and suggestions for the existing problems. Yan Bo, Du Jun and Pan Hong (2019) studied the input and output status, existing problems and Countermeasures of regional collaborative innovation of science and Technology in the Pearl River Delta. Qin Yanhua and Cao Xiyu (2019) analyzed the innovation ability and ranking of 11 cities in Guangdong, Hong Kong and Macao Bay Area by using the analytic hierarchy process (AHP), and put forward 
countermeasures and suggestions for the problems faced by the collaborative innovation of science and technology in Guangdong-Hong Kong-Macau Greater Bay Area.

In terms of spillover effects of collaborative innovation of science and technology, Audretsch and Feldman (2004) through empirical analysis show that the externality of innovation activities, that is, spillover effect can significantly promote technological progress and innovation; bosile, Capello and caragliv (2012) research show that geographical proximity is an important channel for knowledge spillover, but an important channel for collaborative economic growth effect.

For the estimation and application of SpVAR model, Beenstock and Felsenstein (2007) established a spatial panel VAR model including spatial and temporal lag effects. Based on the spatial panel VAR model proposed by Beenstock and Felsenstein (2007), de Assis Cabral, legey and de Freitas proposed a standard procedure for the stability test of this model. Mutl (2009) proposed a threestep estimation procedure for spatial panel VAR model. Monteiro (2009) established a spatial panel VAR model. Through spatial Granger causality test and spatial impulse response function, this paper illustrates the importance of spatial spillover in FDI, trade openness and environmental regulation. Di Giacinto (2010) used the maximum likelihood estimation method of complete information to estimate the structural VAR model and proposed a comprehensive spatial-temporal impulse response function. Márquez and ramajo (2015) established a spatial VAR model to analyze the growth spillover of Spain from 1965 to 2003 . Firstly, the spatial Granger causality test is conducted; secondly, the input effect (push in) and the output effect (push out) of the regional economic growth spillover are estimated. Finally, it shows the short-term and long-term regional growth adjustment process in spatial and temporal dimensions.

This paper analyzes the spatial spillover of the collaborative innovation of Science and technology in Pearl River Delta urban agglomeration by establishing spatial panel SpVAR model.

\section{Research on Spatial Spillover Effect of the Collaborative Innovation of Science and Technology in the Pearl River Delta Urban Agglomeration}

The Pearl River Delta urban agglomeration includes Guangzhou, Shenzhen, Zhuhai, Foshan, Huizhou, Dongguan, Zhongshan, Jiangmen and Zhaoqing. The number of patent applications granted and the R\&D Expenditure of the whole society are shown in Fig. 1 and Fig. 2. As can be seen from Fig. 1, Shenzhen, Guangzhou and Dongguan have a higher number of patent applications granted, followed by Foshan and Zhongshan. It can be seen from Fig. 2 that the R \& D expenditure of Shenzhen and Guangzhou is higher, followed by Zhuhai and Zhongshan. The number of patent applications granted in Pearl River Delta urban agglomeration is highly correlated with the R \& D expenditure of the whole society, and the correlation coefficient between the two variables is 0.874 .

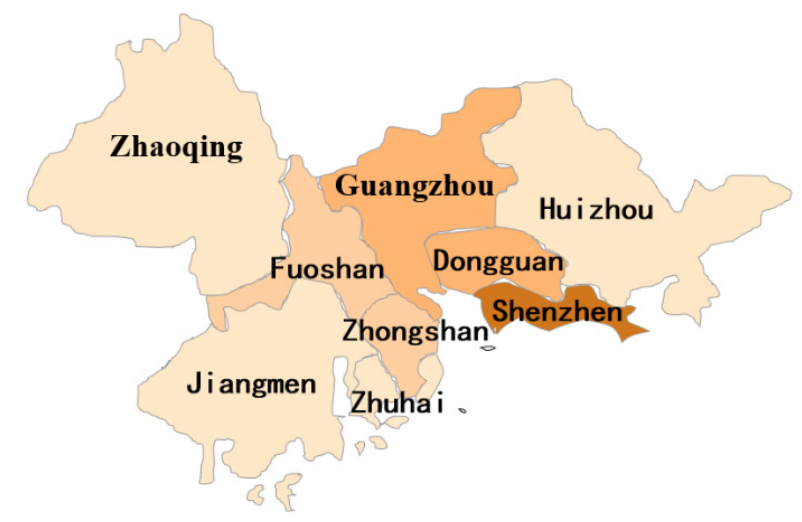

Fig 1. Number of patent applications granted in Pearl River Delta Urban Agglomeration

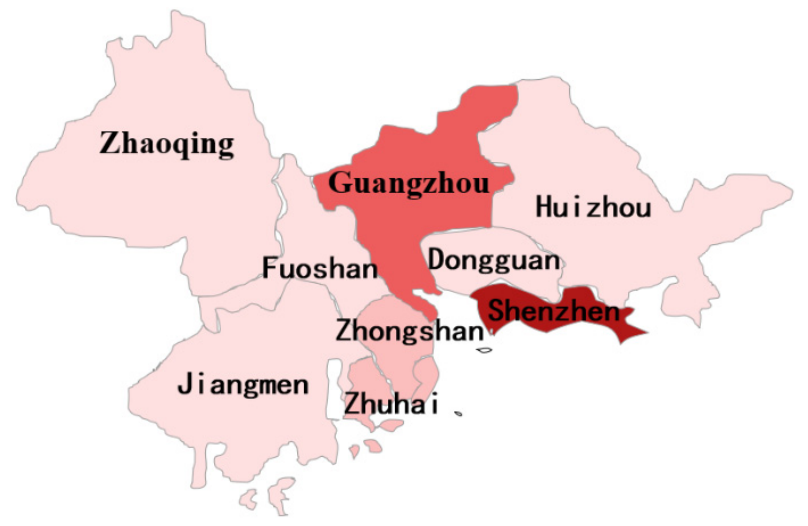

Fig 2. R\&D Expenditure in Pearl River Delta Urban Agglomeration

This paper uses the 2010-2018 panel data to analyze the impact of R \& D inputs on the collaborative innovation of science and technology in Pearl River Delta urban agglomeration. The selection of indicators and variables is shown in TABLE 1. The data is from Guangdong statistical yearbook.

Table1. Selection and definition of variables

\begin{tabular}{|l|c|l|}
\hline \multicolumn{1}{|c|}{ Indicators } & Variables & \multicolumn{1}{|c|}{ Name of variable } \\
\hline $\begin{array}{l}\text { Collaborative Innovation } \\
\text { of Science and } \\
\text { Technology }\end{array}$ & ZL & $\begin{array}{l}\text { The growth rate of } \\
\text { number of patent } \\
\text { applications granted }\end{array}$ \\
\hline R\&D inputs & RD & $\begin{array}{l}\text { The growth rate of R\&D } \\
\text { Expenditure }\end{array}$ \\
\hline
\end{tabular}

Due to the small sample size, this paper selects ZL and $\mathrm{RD}$ to establish spatial dynamic panel VAR (SpVAR) model, and estimates the model by the method of the differential GMM. The specific structure is as follows:

$$
\begin{gathered}
\left\{\begin{array}{c}
Y_{1 i t}=-\alpha_{12} Y_{2 i t}+\left(\beta_{11} Y_{1 i t-1}+\beta_{12} Y_{2 i t-1}\right)+\left(\lambda_{11} Y_{1 i t-1}^{*}+\lambda_{12} Y_{2 i t-1}^{*}\right)+\mu_{1 i}+\varepsilon_{1 i t} \\
Y_{2 i t}=-\alpha_{21} Y_{1 i t}+\left(\beta_{21} Y_{1 i t-1}+\beta_{22} Y_{2 i t-1}\right)+\left(\lambda_{21} Y_{1 i t-1}^{*}+\lambda_{22} Y_{2 i t-1}^{*}\right)+\mu_{2 i}+\varepsilon_{2 i t}
\end{array}\right. \\
\alpha Y_{i t}=\beta Y_{i t-1}+\lambda Y_{i t-1}^{*}+\mu_{i}+\varepsilon_{i t}
\end{gathered}
$$

Among them, $Y_{i t}=\left[\begin{array}{c}\mathrm{ZL} \\ \mathrm{RD}\end{array}\right], \quad Y_{i t}^{*}=\left[\begin{array}{c}\mathrm{ZL}^{*} \\ \mathrm{RD}^{*}\end{array}\right], \mathrm{Y}_{k i t}^{*}=$ $w_{i 1} Y_{k 1 t}+\cdots+w_{i N} Y_{k N t}, \quad i$ is city, $\mathrm{t}$ is time, $\mathrm{k}=1,2, \mu_{i}$ is a fixed intercept item, $\varepsilon_{i t}$ is a random disturbance. 
Assume that $\varepsilon_{i t}$ follows $\mathrm{N}(0, \Omega), \alpha, \beta, \lambda$ and $\Omega$ are given exactly parameters.

In this paper, the spatial distance weight matrix is used to connect the original variable with the corresponding spatial variable. $Z L^{*}$ is a spatial variable corresponding to $\mathrm{ZL}$, and $\mathrm{RD} *$ is a spatial variable corresponding to $\mathrm{RD}$. The space weight matrix $\mathrm{W}$ uses the reciprocal of the distance, and carries on the row standardization processing.

Both sides of equation (2) multiply by $\alpha^{-1}$, then

$$
\begin{aligned}
Y_{i t} & =\alpha^{-1} \beta Y_{i t-1}+\alpha^{-1} \lambda Y_{i t-1}^{*}+\alpha^{-1} \mu_{i}+\alpha^{-1} \varepsilon_{i t} \\
& =B Y_{i t-1}+C Y_{i t-1}^{*}+\eta_{i}+u_{i t}
\end{aligned}
$$

By differential GMM estimation, estimated results are as follows:

$$
\begin{aligned}
B & =\left[\begin{array}{cc}
-0.67739 & -0.53504 \\
-0.45781 & 0.506652
\end{array}\right] \\
C & =\left[\begin{array}{ll}
0.091266 & 2.104229 \\
0.310593 & 1.013537
\end{array}\right]
\end{aligned}
$$

Valid $\operatorname{VAR}(\mathrm{B})$ and $\operatorname{VAR}(\mathrm{C})$ are as follows:

$$
\begin{aligned}
& \operatorname{VAR}(B)=\left[\begin{array}{ll}
0.183062 & 0.359483 \\
0.393128 & 0.771996
\end{array}\right] \\
& \operatorname{VAR}(C)=\left[\begin{array}{ll}
0.295984 & 0.549904 \\
0.635631 & 1.180927
\end{array}\right]
\end{aligned}
$$

According to the above results, the impulse responses are analyzed. Taking Guangzhou (GZ), Shenzhen (SZ) and Zhuhai $(\mathrm{ZH})$ as examples, the impulse response results of all variables in all cities after the impact of different variables in different cities are obtained through impulse response function (see Fig. 3-Fig. 14). Firstly, the empirical results show that a positive shock on ZL of a city will spread to other cities in the Pearl River Delta urban agglomeration, and will have a positive impact on ZL and $R D$ variables of other cities in the second period. Secondly, a positive shock on $\mathrm{RD}$ of a city will make the $\mathrm{ZL}$ and $\mathrm{RD}$ variables of the city and other cities have a positive impact in the second period. Thirdly, ZL and RD variables have positive externalities in the Pearl River Delta urban agglomeration.

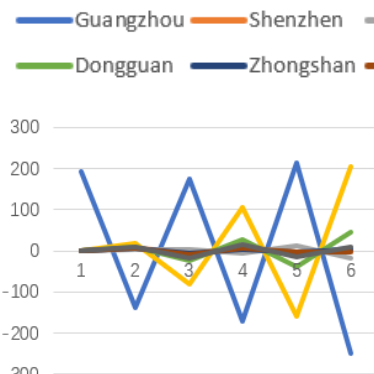

Fig 3. Deviation diagram for all cities on ZL if $\mathrm{GZ}$ is given a shock on $\mathrm{ZL}$

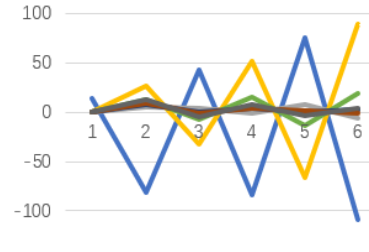

Fig 4. Deviation diagram for all cities on RD if $\mathrm{GZ}$ is given a shock on $\mathrm{ZL}$

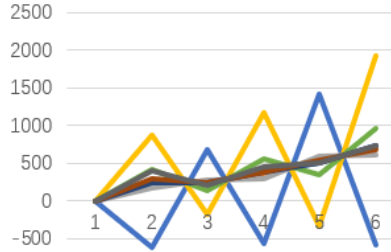

$-1000$

Fig 5. Deviation diagram for all cities on $\mathrm{ZL}$ if $\mathrm{GZ}$ is given a shock on $\mathrm{RD}$

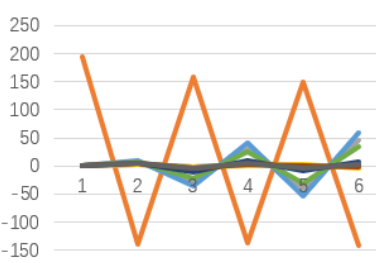

Fig 7. Deviation diagram for all cities on $\mathrm{ZL}$ if $\mathrm{SZ}$ is given a shock on ZL

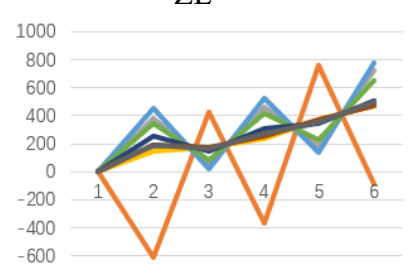

Fig 9. Deviation diagram for all cities on ZL if $\mathrm{SZ}$ is given a shock on $\mathrm{RD}$

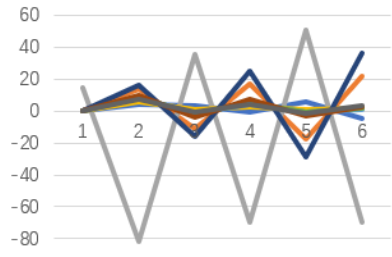

Fig 11. Deviation diagram for all cities on $\mathrm{ZL}$ if $\mathrm{ZH}$ is given a shock on $\mathrm{ZL}$

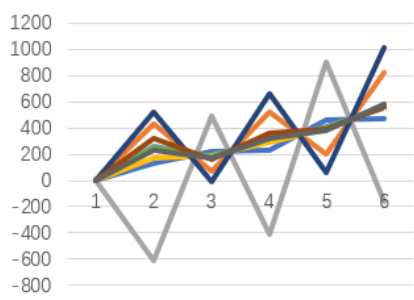

Fig 13. Deviation diagram for all cities on ZL if $\mathrm{ZH}$ is given a shock on RD

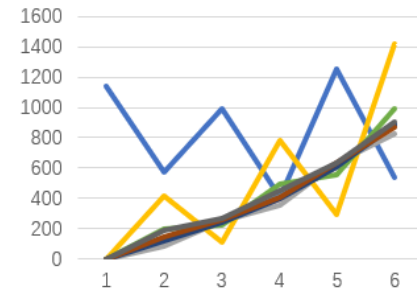

Fig 6. Deviation diagram for all cities on $\mathrm{RD}$ if $\mathrm{GZ}$ is given a shock on $\mathrm{RD}$

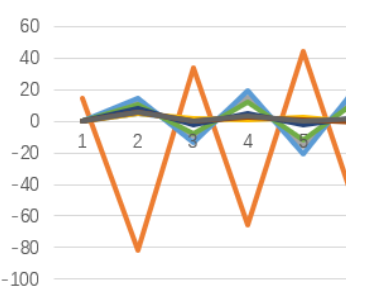

Fig 8. Deviation diagram for all cities on $\mathrm{RD}$ if $\mathrm{SZ}$ is given a shock on ZL

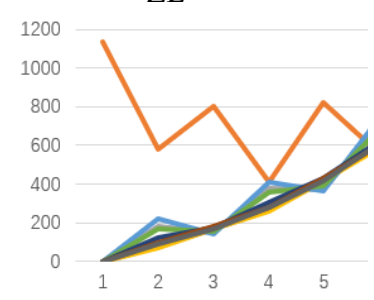

Fig 10. Deviation diagram for all cities on RD if $\mathrm{SZ}$ is given a shock on RD

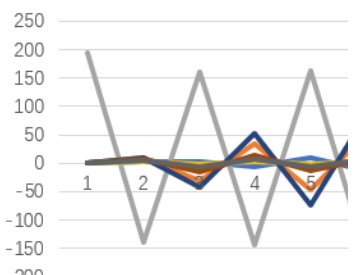

Fig 12. Deviation diagram for all cities on $\mathrm{RD}$ if $\mathrm{ZH}$ is given a shock on $\mathrm{ZL}$

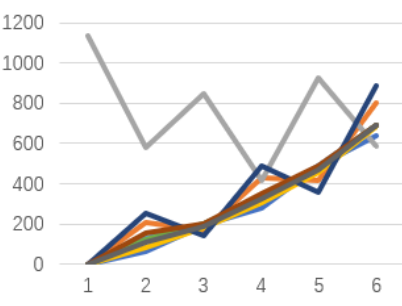

Fig 14. Deviation diagram for all cities on $\mathrm{RD}$ if $\mathrm{ZH}$ is given a shock on $\mathrm{RD}$ 


\section{Conclusions and countermeasures}

\subsection{Conclusion}

This paper uses spatial panel VAR model to study the spatial spillover of the collaborative innovation of Science and technology in the Pearl River Delta urban agglomeration from 2010 to 2018 . The empirical results are as follows.

- A positive shock on the collaborative innovation of Science and technology of a city in the Pearl River Delta urban agglomeration will spread to other cities in the Pearl River Delta urban agglomeration, and will have a positive impact on the collaborative innovation of Science and technology and R \& D input variables of other cities in the second period;

- A positive shock on the $\mathrm{R} \& \mathrm{D}$ input of a city will make the collaborative innovation of Science and technology and R \& D input variables of the city and other cities have a positive impact in the second period;

- The collaborative innovation of Science and technology and R \& D input variables have positive external effects in the Pearl River Delta urban agglomeration.

\subsection{Countermeasures and Suggestions}

- Give full play to the exemplary role of Shenzhen and Guangzhou in the collaborative innovation of science and technology. Shenzhen and Guangzhou are far more capable of technological innovation than other cities. Other cities in the Pearl River Delta should learn from the experience of Shenzhen and Guangzhou in terms of scientific and technological innovation, so as to achieve high-quality economic development.

- Strengthen the exchange and cooperation of the collaborative innovation of science and technology in Pearl River Delta urban agglomeration. Due to the positive spatial externality of collaborative innovation of science and technology, the Pearl River Delta urban agglomeration should be based on the overall situation of the construction of Guangdong Hong Kong Macao Bay area, focus on the new regional development pattern of "one core, one belt and one area" in Guangdong Province, deepen multi-disciplinary and multi-level practical cooperation with Shenzhen and Guangzhou, enhance the coordination and linkage of urban agglomeration development, and promote the optimal allocation of factor resources in the Pearl River Delta urban agglomeration.

- Increase R \& D investment in the Pearl River Delta urban agglomeration. Zhaoqing, Huizhou, Dongguan, Foshan and Jiangmen can further increase $\mathrm{R} \& \mathrm{D}$ investment.

- Improve the input-output rate of collaborative innovation resources of science and technology. For example, Zhuhai's R \& D investment is relatively high, but the number of patent applications granted is insufficient, so it is necessary to further improve the input-output rate of collaborative innovation resources of science and technology.

\section{Acknowledgment}

This work was financially supported by (1) the Zhuhai City's 2019-2020 Annual Philosophy and Social Sciences Planning Project "Research on Influencing Factors and Spatial Spillover Effect of Collaborative Innovation of Science and Technology in Pearl River Delta Urban Agglomeration" (2019ZC145) (2) School-level scientific research project of Beijing Institute of Technology, Zhuhai. "Research on the Influencing Factors and Spatial Spillover of Collaborative Innovation of Science and Technology in the Pearl River Delta Urban Agglomeration" (XK-2019-09).

Sponsors:(1) the Zhuhai City's 2019-2020 Annual Philosophy and Social Sciences Planning Project "Research on Influencing Factors and Spatial Spillover Effect of the Collaborative Innovation of Science and Technology in the Pearl River Delta Urban Agglomeration"(2019ZC145) (2) School-level scientific research project of Beijing Institute of Technology, Zhuhai. "Research on the Influencing Factors and Spatial Spillover of the Collaborative Innovation of Science and Technology in the Pearl River Delta Urban Agglomeration" (XK-2019-09).

\section{References}

1. Wang Weidong, "Research on collaborative innovation development mechanism of Yangtze River Delta Urban Agglomeration," Enterprise economy, 2011,30(12):125-128(in Chinese).

2. Yan Bo, Du Jun and Pan Hong, "Current situation, problems and Countermeasures of science and Technology Collaborative Innovation in Pearl River Delta region," Research on science and technology management, 2019,39(01):87-96(in Chinese).

3. Qin Yanhua and Cao Xiyu, "Research on Collaborative Innovation of science and technology of Urban Agglomeration in Guangdong, Hong Kong and Macao." Journal of central China Normal University (NATURAL SCIENCE EDITION), 2019,53(02):255-262(in Chinese).

4. Audretsch, David B., and Maryann P. Feldman. "Knowledge spillovers and the geography of innovation." Handbook of regional and urban economics. Vol. 4. Elsevier, 2004. 2713-2739.

5. Basile, Roberto, Roberta Capello, and Andrea Caragliu. "Technological interdependence and regional growth in Europe: Proximity and synergy in knowledge spillovers." Papers in Regional Science 91.4 (2012): 697-722.

6. Beenstock, Michael, and Daniel Felsenstein. "Spatial vector autoregressions." The Econometric Analysis of 
Non-Stationary Spatial Panel Data. Springer, Cham, 2019. 129-161.

7. de Assis Cabral J, Legey L F L, de Freitas M V. A STANDARD PROCEDURE FOR TESTING THE STABILITY OF SPATIAL VECTOR AUTOREGRESSIVE MODELS (SpVAR)

8. Mutl, Jan, and Michael Pfaffermayr. "The Hausman test in a Cliff and Ord panel model." The Econometrics Journal 14.1 (2011): 48-76.

9. Monteiro, Jose-Antonio. "Pollution Havens: a Spatial Panel VAR Approach." (2009).

10. Di Giacinto, Valter. "On vector autoregressive modeling in space and time." Journal of Geographical Systems 12.2 (2010): 125-154.

11. Márquez, Miguel A., Julián Ramajo, and Geoffrey JD Hewings. "Regional growth and spatial spillovers: Evidence from an SpVAR for the Spanish regions." Papers in Regional Science 94 (2015): S1-S18. 